\title{
Research Review and Prospect on Management Innovation Performance
}

\author{
Libo Liư, a, Qiang Sun²,b \\ ${ }^{1}$ City Institute, Dalian University of Technology, Dalian, China \\ ${ }^{2}$ Management College, Shandong University of Technology, Dalian, China \\ aliulibo@dlut.edu.cn, byssunqiang@163.com
}

\begin{abstract}
Keywords: management innovation performance; organizational learning; knowledge management; dynamic capabilities

Abstract. Based on the literature review on the research progress of management innovation (MI) theory, the study concludes the existing literatures into four interrelated perspectives, including organizational learning (OL), knowledge management (KM), dynamic capabilities (DC) and external environment (EE) of organization, and put forward the integrated research system based on the interrelated perspectives. In addition, the study concludes the research methods into two categories: the empirical study method and the statistical analysis method. Finally, it proposes the uncovered problems and directions by current related research in five aspects: the performance evaluation system of management innovation, deepening the key factors affecting management innovation performance (MIP), integrating the effect paths of MIP, complementing the research on improvement mechanism of MIP and the extension of related research methods.
\end{abstract}

\section{Introduction}

As market competition intensifies and the pace of technological change accelerates, firms need to renew themselves. The challenge is not only offering new products and services, but also changing the nature of management within organizations. In order to maintain competitiveness, firms not only need to continuously create new strategies, products and features, but also need to constantly generate new management methods. It is seen as a catalyst, to some extent, for organizational self-renewal. Early studies such as Schumpeter (2009) proposed the concept of innovation firstly, which lead to appear research boom on innovative theory, but most scholars have directed their attention towards technology innovation. Until Stata (1989) proposed the concept of MI, scholars began to shift their attention to other areas of innovation theory except technology innovation, such as process innovation, service innovation, strategic innovation, public management innovation, structural innovation et al. Birkinshaw et al.[1] define MI as 'the generation and implementation of a management practice, process, structure, or technique that is new to the state of the art and is intended to further organizational goals'. Numerous studies prove that MI can positively impact organizational performance and help to achieve business goals and enhance competitive advantage.

\section{Research Progress Review on Management Innovation Theory}

The earliest, Schumpeter (1991) expounded the important role of innovation on economic development, and today innovation has become a key direction of social science research, whose research has been extended to many areas, such as business management, finance, education, culture and services et al. Based on the definition of Schumpeter, innovative research developed gradually into two branches: one is technological innovation which is characterized in technological change and spread, and the other is MI which aims at business management or governance. However, technological innovation in electronics, machinery, equipment, communications, and other manufacturing industries still dominate innovation research, until the 1980s, with the rise and development of management science, MI gradually attracted t researchers' eyes. Stata (1989) 
proposed the concept of MI for the first time, when he was striving to find the origins which lead Analog Device to miss its five-year goals. As a result, he was firmly convinced that the external environment such as the malaise in the U.S. electronic industry and the strong dollar, was only part of the problem: something was also wrong internally, and it had to be fixed. Analog Device had the largest share of its niche market in high-performance linear integrated circuits, and had the vest designers, technologists, excellent relations with a highly motivated workforce and adequate investment. The only conclusion was that there was something about the way of managing the company that was not good enough, and the bottleneck was management innovation, but not technological innovation in the traditional sense. Hereafter, scholars such as Benghozi (1990), Hamel (2006), Birkinshaw (2007, 2008), Mol (2009), extended, refined and deepened the MI theory on the basis of defining the concept, characteristics and connotation of MI. Since MI was introduced to China by Rui Ming-jie (1994) and Chang Xiu-ze (1994) in 1990s, Chinese scholars including Zhang Gang (1999), Li Yan and Wei Feng (2003), Li Yi (2008), Lin Hai-fen and Su Jing-qin (2010, 2011, 2012) et al. have carried out a number of studies respectively from theoretical and empirical research.

At present, most scholars have reached a consensus practically on the concept and connotation of MI. MI is different from technology innovation, and is a management concept or practice which can achieve resources integration with high efficiency by the change of management modes and the introduction of new management methods based on firm's internal and external environment. On the whole, subsequent studies on MI were launched around the following four dimensions (table 1).

Table 1. Summary about research dimensions of MI

\begin{tabular}{|c|c|c|}
\hline $\begin{array}{c}\text { Research } \\
\text { dimensions }\end{array}$ & Representatives and their main literature & Research focus \\
\hline Motivation & 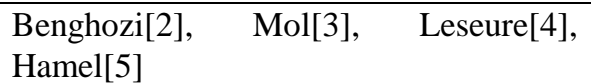 & $\begin{array}{l}\text { Performance decline, loss of competitiveness, malaise } \\
\text { in most of industries, low of productivity levels }\end{array}$ \\
\hline $\begin{array}{l}\text { Influencing } \\
\text { factors }\end{array}$ & Marisa[6], Nekane[7], Jonilto [8] & $\begin{array}{l}\text { Innovation concept, organizational structures } \\
\text { (organizational culture and designs, development } \\
\text { strategies of employees, organizational systems and } \\
\text { resources et al.), innovation strategies, managers, } \\
\text { external environment, et al. }\end{array}$ \\
\hline $\begin{array}{l}\text { Implementation } \\
\text { processes }\end{array}$ & $\begin{array}{l}\text { Hamel[9], Su Jing-qin(2010), } \quad \text { Lin } \\
\text { Hai-fen (2013) }\end{array}$ & $\begin{array}{l}\text { New management innovation and imported } \\
\text { management innovation; division of management } \\
\text { stages, work content and characteristics, etc. }\end{array}$ \\
\hline $\begin{array}{l}\text { Impact on } \\
\text { organizational } \\
\text { performance }\end{array}$ & Cristian (2012), YonJin(2013) & $\begin{array}{l}\text { How management innovation affects organizational } \\
\text { performance and the relations between the two }\end{array}$ \\
\hline
\end{tabular}

Table 1 shows that MI theory involved multiple dimensions and recent researches focused on four areas including motivation, influencing factors, implementation processes and impact on organizational performance which was undertaken based on the macro level. However, there is little literature on the issues from micro-level, such as definition of novelty, details and culture building of management innovation.

\section{Research Perspectives of MIP}

Reviewed by the previous studies, we can note that scholars have carried out extensive research on MIP. The ultimate goal of MI lies in improving organizational operation efficiency and performance which are the determinants to maintain competitive advantages and create values for firms. Based on generalizing the main factors which affect MIP, we summarize four related perspectives, including OL, KM, DC and EE, which enhance MIP together.

\section{Organizational Learning Perspective}

OL appears in social structure of organizations and is a systematic process in which knowledge is organized, created and utilized by interaction and sharing of knowledge through the whole firm. When facing uncertainty of external environment, OL is a strategic approach to obtain long-term sustainable development and keep market competitiveness. Therefore, strong learning abilities of 
firms can promote innovation, increase environment adaptability and strengthen innovation performance. So it can clearly be seen that OL has important influence on MIP, which can be reflected in three aspects.

\section{(1). Learning Climate}

Because of the speed with which new products, processes and services arise, organizations must be able to generate and implement new management practices, structures and tools to adapt to new situations or anticipate changes in the external environment. In this sense, the OL, as an organizational attribute, is crucial for the success of organizations (Jonilto, 2013), and especially the learning climate is foundation and precondition for building lasting advantages in relation to rivals. Given the independence of MIP, Alberto (2007) studied the relationship between organizational learning, leadership style, management innovation and organizational performance by empirical study, whose data analysis from 408 large firms proved that OL had a stronger direct influence on innovation than leadership style, and the learning climate had the most important impact on OL. Additionally, leadership style positively and significantly influenced learning climate, and MI also positively affected organizational performance.

\section{(2). Learning Resources}

MI is an important prerequisite for firms' success, and successful innovation demands the firms to form new organizational capabilities which can appropriately deal with external competition from industrial market and internal pressure from performance, in whose formation learning resources are prominent factors influencing management innovation which positively associate with innovation performance. Based on the resource-based view and organizational learning perspective, YonJin's research (2013) focused on the effects of European firms' innovative capabilities and experience on their acquisition performance when targeting United States firms. He concluded that both innovative capabilities and learning resources have a positive effect on acquisition performance and European firms need to reinforce their innovative capabilities, commit to accumulating experiences and excavate learning resources to enhance innovation performance.

\section{(3). Learning Style}

Different styles of OL affect MIP differently, in addition, the same type of learning plays different roles in a wide variety of innovation practices. Li Yi $(2006,2008)$ divided OL styles into three dimensions including advanced levels of OL, introspection and correction of reasons behind problems caused by OL, and changes in knowledge stock, which were integrated into four learning styles: adjusting learning, reflection learning, theoretical learning and practical learning and it was further confirmed that this four learning styles have significant effect on MIP.

\section{Knowledge Management Perspective}

According to the existing literature, researches about the effects of KM on MIP generally involve two aspects. One is interaction mechanism between knowledge management, management innovation and organizational performance using qualitative research methods, such as Tsung-Hsien (2011) confirmed that management innovation practices can enhance organizational learning and knowledge management capacities which contribute to promote human resource management performance from the view of human resource management practices; Lin Hai-fen and Su Jing-qin (2010) verified that the process effectiveness of MI can be enhanced by improving knowledge management capabilities.

The other is empirical research and building models, which usually takes KM as a mediating variable in order to intuitively show the influence process and degree of KM on MIP, such as Douglas (2006) considered KM and OL as a community which plays a important role on innovation performance in economic model; Hsing-Er (2013) proposed hypothesize that strong management innovation capability can generate better organizational performance and verified its correctness from the perspective of organizational ambidexterity. Noruzy and Vahid (2013) determined relations between transformational leadership, OL, KM, organizational innovation, and organizational performance among Iranian manufacturing companies through structural equation modeling, as a 
result, found that OL and KM directly influenced organizational innovation, whereas OL and organizational innovation directly influenced organizational performance among manufacturing firms. In summary, research on MIP abroad has formed theoretical system and methodology from the perspective of KM, but this research is still in its infancy in China, and there are a small number of scholars engaged in this field, such as Lin Hai-fen (2010), Wang Yan-qiu and Ge Hong-yan (2010) and Xie Hong-ming (2009). Thus, this field has considerable research to expand in China.

\section{Dynamic Capability Perspective}

DC is a kind of ability that firms integrate, reconstruct and build internal and external capacities or resources of organization and the necessary safeguards of achieving MI and directly affects the efficiency of MI positively. MI, which lies on certain organizational system constituted by complicated elements and links, needs the DC of continuous renewing, reorganizing and integrating resources to support the realization of innovation. Lin Hai-fen and Su Jing-qin (2012) proposed a measure method of management innovation effectiveness from process perspective, and divided DC into four dimensions including sensing capability, learning capability, relationship capability, integration and coordination capability, cleaned the interrelationship among four dimensions of DC, and uncovered the internal function mechanism and affecting approach of different dynamic capability dimension of different management innovation step. Their study absolutely analyzed the direct effect of DC on MIP, but from the review of relevant research, it is not difficult to find that few studies involve MIP only from the single perspective of DC, and many scholars comprehensively analyze other influencing factors except DC, such as dual perspectives composed by DC and KM, which is more concentrated research on the combined effect factors on MIP.

\section{External Environment Perspective}

OL, KM and DC affect MIP within the organization, but in the fact, external environment also positively influences the MIP, such as market efficiency, market orientation, organizations cooperation, social capital, etc. Felix (1999) investigated the embeddedness of strategy into the macro- and micro-environments, and suggested that market orientation, manufacturing orientation, human resource management and product innovation significantly influence marketing effectiveness and organizational performance and that marketing effectiveness is shown to contribute significantly to financial performance. Organizational and environmental factors in the process of MI can moderate the relationship between management innovation and organizational performance and the market orientation and environmental dynamism are specially significant on relationship between the both (Evelyn et al., 2013). DC and inter-organizational collaboration have been highlighted as two critical determinants of firms' performance, but the firm's external collaboration strategy has been advocated as a means by which firms develop capabilities, and affects positively market performance in the turbulent environment. From the perspective of social network, Liang Wei's study (2013) shows that MIP is positively influenced by social network, whose variables involve network size, network heterogeneity and network durability, and that the larger network size, higher heterogeneity and strong durability of social network can create better innovation performance. Management innovation activities in organization are always intertwined with social networks, and this intricate relationship generates a a special organizational resource 'social capital' which can promote organizational innovation performance and competitiveness. The literature review tells us the related studies are limited to two aspects 'market orientation and social networks' from the external environment perspective and obtain less research results. Thus, we detect a larger research scope about the external environment perspective.

In conclusion, the four research perspectives of MIP emphasize the impact of different ways and methods of MI on organizational performance, which microscopically elaborates the MIP based on a single perspective or a combination of several perspectives and has important reference value management practices of firms. From the effect path of MIP, there is a relationship of mutual influence between the four perspectives, which ultimately affect the performance of management innovation (Figure 1.). 


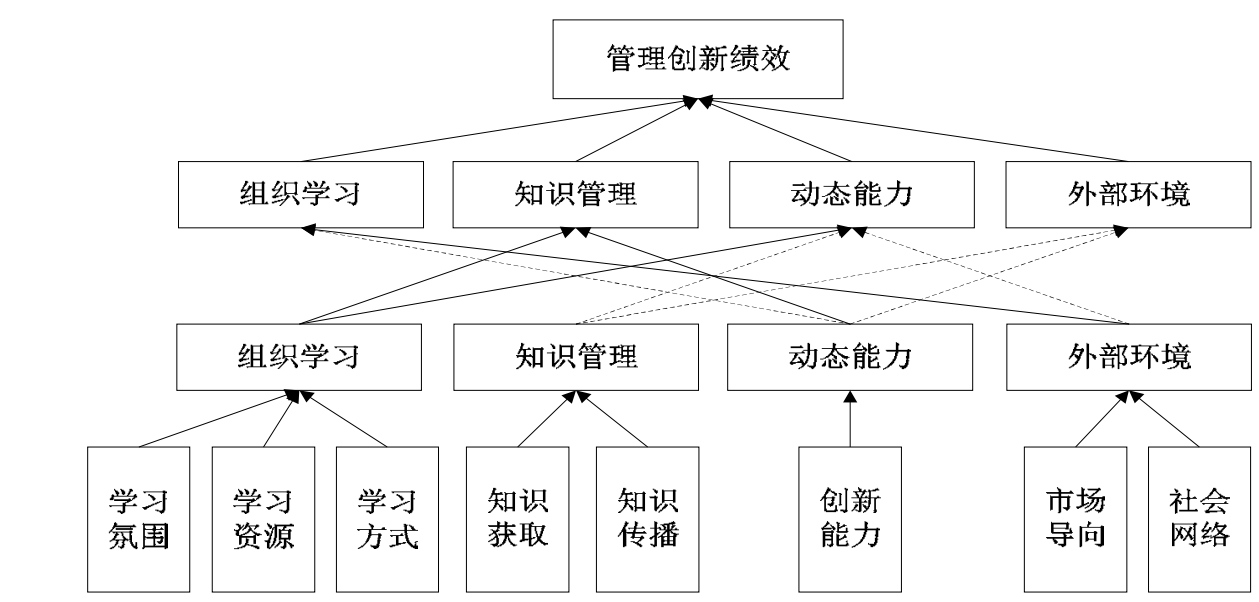

Notice: Dashed arrows indicate the affecting relationship of having not been involved in current studies.

Figure 1. The integrated graph of the related research perspectives about MIP

\section{Conclusions and Future Research Prospect}

From the literature review above, it can be easy to find that MIP has became an important branch in the field of innovation research, and that scholars gain some valuable results in theoretical and practical research. With the deepening of the study, management innovation and organizational performance are integrated into a single research direction, which break through the macro-scope of the relationship between organizational innovation and performance and focus on the paths and methodology affecting MIP. Despite this, there are still a lot of issues to be further explored and discussed on MIP in theory and practice.

\section{Building Evaluation System on MIP}

Management efficiency and management effectiveness can reflect the value of MI, and the former focuses on the improvement of innovative process efficiency brought by management innovation methods, but the latter follow closely the results of MI (management innovation performance in the narrow sense). According to theoretical studies, firm's MI in a broad sense includes technological innovation and management innovation, then technological innovation is Stripped out from management innovation by some theorists and form a management innovation mode in the narrow sense, which reflects the correlation and difficult separation between management innovation and technology innovation. In addition, management innovation performance lags behind technological innovation performance, and management innovation performance is reflected after the implementation of technological innovation a long time. Thus, it is necessary to build the evaluation system on MIP and select object, index and method of evaluation based on scientific evaluation principles.

\section{Excavating the influencing factors of MIP in the internal and external environment of organization}

Through literature review, the influencing factors of management innovation performance are divided into two aspects: internal environmental factors and external environmental factors. Organizational learning, knowledge management and dynamic capabilities are all based on the internal perspective of the organization, and analyze its impact on innovation performance. Market orientation and social networks are external factors of the organization, studying the impact of the external environment on innovation performance. It is necessary to further explore the internal and external environmental factors, such as corporate culture, organizational structure model, resource management method, internal organization cooperation, organizational leaders and other internal factors.

\section{Improve management innovation performance improvement mechanism}

Management innovation stems from the organization's perception of current and potential performance degradation, which can lead to the creation of management innovation ideas. In the face 
of the decline of organizational performance, researchers try to integrate management resources, management tools and management methods through organizational learning and knowledge management to achieve organizational change and organizational progress. In this process, the organization needs to have good dynamics and dynamic capabilities. It is a booster for performance improvement, so it is critical that an organization has organizational learning, knowledge management, and dynamic capabilities. At the same time, the realization of management innovation performance depends on the external environment in which the organization is located. The good market atmosphere and social network all positively affect the performance improvement. Organizational learning, knowledge management, dynamic capabilities, and the external environment of the organization have different influences at different stages of management innovation creation, decision making, and implementation. Expand the interaction between the four perspectives and explore its integrated impact on management innovation performance. The dotted arrow in Figure 1 is the relationship that has not been covered in the existing research and can be further studied. In addition, the effective implementation of management innovation practices requires the acquisition and effective allocation of relevant resources within and outside the organization.

\section{Expand related research methods}

At present, the research on management innovation performance mostly uses empirical research and statistical analysis. There are limitations of research methods. It is necessary to further expand the research methods, especially using multiple methods to explore the same problem, which can enhance the authenticity and persuasion of the research conclusions.

\section{References}

[1] Julian Birkinshaw, Gary Hamel, Michael J. Mol. Management Innovation. Academy of Management Review. Forum33 Vol4(2008), p825-845

[2] Pierre Jean Benghozi. Managing Innovation: From Ad hoc to Routine in French Telecom. Forum11 Vol4(1990), p531-554

[3] Michael J Mol, Julian Birkinshaw. The sources of Management Innovation: When Firms Introduce New Management Practices. Journal of Business Research, Forum12 Vol62(2009), p1280

[4] Leseure M J, Bauer J, Birdi K. Adoption of Promising Practices. International Journal of Management Review. Forum5 Vol6(2004), p180

[5] Julian Birkinshaw, Gary Hamel. Special Report Management Innovation. Business Strategy Review. Forum1 Vol18(2007), p62-65

[6] Marisa Smith. Factors Influencing An Organization's Ability to Manage Innovation: A Structured Literature Review and Conceptual Model. International Journal of Innovation Management. Forum4 Vol12(2008), p655-676

[7] Nekane Aramburu. Structural Capital, Innovation Capability, and Company Performance in Technology-Based Colombian Firms. Proceedings of the International Conference on Intellectual Capital, Knowledge Management \& Organizational Learning, 2013: 20-29

[8] Jonilto Costa Souza. The Innovation Process in the Organizational Context: An Analysis of Helping and Hindering Factors. Brazilian Business Review. Forum3 Vol10(2013), p108-129

[9] Gary Hamel. The Why, What, How of Management Innovation. Harvard Business Review. Forum3 Vol10(2006), p72-84 